\title{
Profile Matching Untuk Sistem Pendukung Keputusan Pemilihan Vendor Maintenance Server dan Jaringan
}

\author{
Khoirun Nisa ${ }^{1}$, Entin Sutinah ${ }^{2}$ \\ ${ }^{1}$ STMIK Nusa Mandiri Jakarta \\ e-mail: khoirunnisa.khn@gmail.com \\ ${ }^{2}$ AMIK BSI Jakarta \\ e-mail: entin.esh@bsi.ac.id
}

\begin{abstract}
Abstrak
Memilih pemasok yang tepat atau vendor diantara pemasok yang ada adalah isu penting bagi top manajemen. Proses penentuan vendor pada PT. Gema Graha Sarana dilakukan secara manual, yang diawali dengan pengumpulan informasi melalui presentasi dari setiap calon vendor. Setelah itu dilakukan rapat pimpinan untuk membahas tentang kelebihan dan kekurangan masing-masing vendor. Rapat pimpinan perusahaan menggunakan sistem votting sehingga cara tersebut dinilai masih kurang objektif dan tidak menutup kemungkinan penilaian dilakukan secara subjektif. Saat ini sudah berkembang pesat teknologi dalam segala bidang salah satunya teknologi dalam penentuan pengambilan keputusan, oleh karena itu untuk membantu dalam pemecahan masalah tersebut perlu dilakukan sebuah pendekatan dengan menggunakan sebuah metode sistem pendukung keputusan salah satu nya dengan menggunakan metode Profile Matching dengan tahapan yaitu menentukan kriteria, perhitungan pemetaan gap, melakukan pembobotan, perhitungan core factor dan secondary factor, perhitungan nilai total, dan perhitungan untuk menentukan perangkingan. Tujuan dari penelitian ini adalah menentukan vendor yang cocok agar mampu menyediakan layanan jasa maintenance server dan jaringan sesuai kebutuhan. Sehingga dari tahapan-tahapan tersebut diperoleh sebuah hasil keputusan untuk memilih vendor yang akan diajak kerja sama dalam melakukan pekerjaan maintenance server dan jaringan dengan memilih PT. Nusa Network Prakarsa.
\end{abstract}

Kata Kunci: Pemilihan Vendor, Profile Matching, Sistem Pendukung Keputusan.

\begin{abstract}
Selecting the right supplier or vendor among existing suppliers is an important issue for top management. The process of determining vendor at PT. GemaGrahaSarana, Tbk is done manually, which begins with the collection of information through the presentation of each potential vendor. After that conducted a leadership meeting to discuss the advantages and disadvantages of each vendor. Company leadership meeting using the voting system so that way is considered still less objective and did not rule out the assessment is done subjectively. Nowadays, technology has been developed in all fields, one of them is technology in determining decision making, therefore to assist in solving the problem it is necessary to do an approach by using a method of decision support system of one of them by using method matching profile with stages that is Determining Criteria, Gap Mapping Calculation, Weighting, Calculation of Core Factor and Secondary Factor, Total Value Period, and Calculation for Determining Ranking. The purpose of this research is to determine the suitable vendors to be able to provide server and network maintenance services as needed. So from these stages obtained a decision to select a vendor who will be invited to work together in doing maintenance work server and network by choosing PT. Nusa Network Prakarsa.
\end{abstract}

Keywords: Vendor Selection, Profile Matching, Decision Support System. 


\section{Pendahuluan}

Pemilihan vendor yang tepat diantara vendor yang ada adalah isu penting bagi top manjemen (Arini, 2015). Pemilihan vendor adalah permasalahan multi kriteria dimana setiap kriteria yang digunakan mempunyai kepentingan yang berbeda dan informasi mengenai hal tersebut tidak diketahui secara tepat(Kurniawan, Hasibuan, \& Nugroho, 2017).

Selama ini penentuan vendor pada PT. Gema Graha Sarana dilakukan secara manual, yang diawali dengan pengumpulan informasi melalui presentasi dari setiap calon vendor. Setelah itu dilakukan rapat pimpinan untuk membahas tentang kelebihan dan kekurangan masing-masing vendor. Rapat pimpinan perusahaan menggunakan sistem votting sehingga cara tersebut dinilai masih kurang objektif dan tidak menutup kemungkinan penilaian dilakukan secara subjektif.

Dalam hal ini pemilihan vendor yang berdasarkan penawaran harga yang rendah sudah tidak efisien lagi. Untuk mendapatkan kinerja rantai pasok yang maksimal harus menggabungkan kriteria lain yang relevan dengan tujuan perusahaan. Berdasarkan hal tersebut sebuah perusahaan membutuhkan bantuan vendor information technology sebagai penyedia informasi teknologi. Perusahaan perlu untuk memilih vendor yang tepat untuk turut serta bekerja sama. Pemilihan vendor yang tepat dilakukan dengan melihat kriteria vendor tersebut sehingga diharapkan dapat meminimalkan resiko yang akan timbul. Selain itu juga diharapkan terjalinnya hubungan yang baik antara perusahaan dan vendor.

Sistem pendukung keputusan pengangkatan jabatan karyawan dengan menganalisa Aspek Kapasitas Intelektual, Aspek Sikap Kerja dan Aspek Perilaku yang dikategorikan dalam core factor dan secondary factor menggunakan metode gapAnalysis yang dikombinasikan dengan metode Profile Matching. Hasil penelitian yang didapat adalah sebuah sistem pendukung keputusan yang mampu memberikana evaluasi kinerja bagi karyawan yang akan dipromosikan. (Adhar, 2014)

Penggunaan metode Profile Matching dilakukan untuk memberikan penilaian, penentuan gap dan pembobotan kriteria dan Metode AHP digunakan untuk menghitung matrik perbandingan berpasangan, eigen, skala prioritas, eigen maksimal consistency index (Cl) dan consistency ratio $(\mathrm{CR})$. Nilai $\mathrm{CR}$ digunakan dalam menentukan urutan proposal yang akan didanai oleh BLM. Hasil dari penelitian ini adalah perangkat lunak sistem pendukung keputusan untuk penilaian proposal PNPM-MPd yang dapat menentukan ranking nilai dari yang tertinggi sampai terendah.(Mufid, 2014)

Penerapan Metode Profile Matching dilakukan juga dalam penentuan Supplier Suku Cadang Mobil dengan menggunakan empat kriteria yaitu harga, kualitas barang, ketepatan waktu pengadaan barang dan keramahan. Hasil implementasi yang telah dilakukan dinilai mampu memberikan solusi berupa alternatif keputusan dalam bentuk nilai yang dirangking. (Permana, 2016)

Penggunaan system pendukung keputusan dengan metode profile matching dilakukan dalam menentukan sales terbaik yang akan dipromosikan menjadi sales manajer.(Sutinah, 2017)

Profile Matching dapat membantu proses mekanisme perhitungan kriteria dalam pengambilan keputusan terhadap suatu objek yang dinilai dan dilihat dari tingkat variabel prediktor yang ideal yang harus dimiliki calon karyawan tetap. (Hakim, Sudiarjo, \& Efrida, 2017)

Metode Fuzzy ANP dan Topsis digunakan dalam pendukung keputusan evaluasi pemilihan vendor dengan menilai para vendor sehingga didapatkan evaluasi kinerja berdasarkan sepuluh kriteria yaitu waktu pengiriman, jumlah pengiriman, packaging, kualitas produk, produk ramah lingkungan, harga produk, cara pembayaran garansi, sistem komunikasi dan responsiveness yang dibagi menjadi empat cluster yaitu delivery, quallity, price dan service.Hasil penelitian berupa hasil penelitian keseluruhan kriteria untuk periode 1 tahun terakhir dan hasil akhir berupa SOP Evaluasi kinerja vendor. (Pohan \& Wibowo, 2017)

Pada penelitian ini Metode Profile Matching akan digunakan dalam pemilihan vendor pada PT. Gema Graha Sarana. Tahap awal adalah penentuan kriteria, perhitungan pemetaan gap, melakukan pembobotan, perhitungan core factor dan secondary factor. Kemudian menghitung nilai total yang diperolah dari pembagian dari presentase dari nilai core factor dan 
secondary factor sehingga dapat terlihat urutan ranking yang dihasilkan.

\section{Metode Penelitian}

Penelitian ini dilakukan di PT Gema Graha Sarana, untuk menentukan sebuah keputusan dalam pemilihan vendor maintence server dan jaringan kemputer dengan beberapa metode penlitian yaitu :

\section{Metode Pengambilan Responden}

Responden yang diambil dalam penelitian ini adalah responden ahli yaitu IS Dept. Head, Section Head dan Staff Sistem Administrator yang ahli di bidang Maintenance server dan Jaringan serta bersertifikasi.

Adapun pertimbangan pengambilan responden yang berdasarkan kategorisasi atau latar belakang responden diatas, antara lain agar penilaian terhadap vendor maintenance server dan jaringan ini lebih variatif dan objektif. Tabel 1 menunjukan daftar lengkap para responden ahli :

Tabel 1. Responden Ahli

\begin{tabular}{|c|l|c|}
\hline No & \multicolumn{1}{|c|}{ Responden } & Jumlah \\
\hline 1 & IS Departement Head & 1 orang \\
\hline 2 & Section Head & 1 orang \\
\hline 3 & $\begin{array}{l}\text { Staff System } \\
\text { Administrator }\end{array}$ & 1 orang \\
\hline \multicolumn{2}{|c|}{ Jumlah } & 3 orang \\
\hline
\end{tabular}

\section{Metode Pengumpulan data}

Menurut cara memperolehnya data yang digunakan dalam penelitian ini adalah data primer yaitu data yang dikumpulkan oleh peneliti langsung dari narasumber ahli dan tempat objek penelitian. Metode pengumpulan data yang digunakan pada penelitian ini yaitu :
1) Studi Pustaka

Studi Pustaka dilakukan untuk mencari data-data yang bersifat teoritis dan berhubungan dengan penelitian yang sedang dilakukan.

2) Wawancara

Wawancara dilakukan dengan tanya jawab secara langsung kepada tiga responden ahli yaitu IS Dept. Head, Section Head dan Staff Sistem Administrator PT Gema Graha Sarana untuk memperoleh informasi yang lengkap dan jelas terkait dengan kriteria dalam pemilihan vendor maintenance server dan jaringan.

3) Kuesioner

Untuk mendapatkan data-data yang dibutuhkan, pengumpulan data dilakukan melalui kuesioner bersifat close question yang berupa pertanyaanpertanyaan yang dibuat penulis berdasarkan kerangka acuan kerja (Term of Reference) PT. Gema Graha Sarana. Pertanyaan-pertanyaan yang dibuat adalah untuk mengetahui nilai setiap kriteria dari masing-masing alternatif vendor. Skala pengukuran instrumen penelitian menggunakan Skala Likert.

\section{Metode Pengolahan data}

Profile matching adalah sebuah mekanisme pengambilan keputusan dengan asumsi terdapat variabel prediktor ideal yang harus diiliki oleh pelamar, bukannya tingkat minimal yang harus dipenuhi atau dilewati (Kusrini, 2007).

Gap merupakan sebuah perbedaan antara profile yang dimiliki oleh masing-masing alternatif dengan profile standar (Kusrini, 2007). Hal tersebut dapat dihitung dengan rumus persamaan (1).

Gap $=$ Profil Atribut- Profil Target 


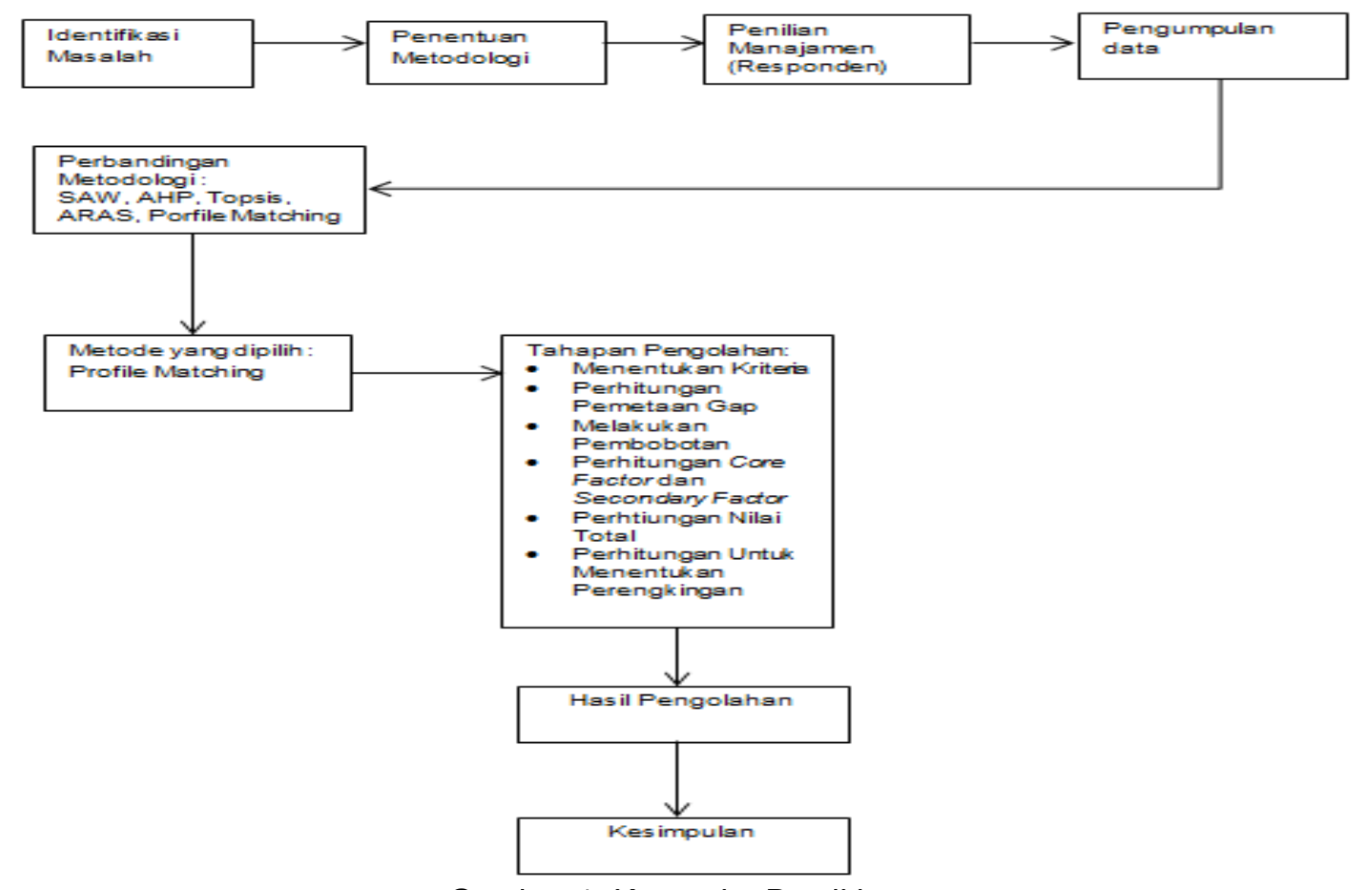

Gambar 1. Kerangka Pemikiran

Sumber : Hasil Penelitian (2018)

\section{Hasil dan Pembahasan}

Pada point ini membahas mengnai hasil dari penelitian dan membahas menganai langkah-langkah pengolahan data dengan menggunkan profile matching dengan tahapannya yaitu:

\subsection{Menentukan Kriteria Penilaian}

Pada proses menentukan kriteria penialaian, Alternatif Vendor yang akan dinilai terdiri dari tiga perusahaan yaitu alternatif ke satu PT. Mitra Integrasi Informatika, alternatif ke dua: PT. Iproteksi Telematika dan alternatif ke tiga PT. Nusa Network Prakarsa, masing masing alternatif akan dinilai oleh stakeholder, untuk menentukan kriteria penilaian dalam memilih vendor terbaik terdapat 4 kriteria yaitu : harga, jumlah teknisi profesional, metodologi pelaksanaan pekerjaan dan pengalaman perusahaan, untuk masingmasing kriteria akan diberikan simbol. Seperti pada tabel 2 :

Tabel 2.Tabel Kriteria Penilaian

\begin{tabular}{|c|c|}
\hline Kriteria & Nama Kriteria \\
\hline C1 & Harga \\
\hline C2 & JumlahTeknisi Professional \\
\hline C3 & MetodologiPelaksanaanPekerjaan \\
\hline C4 & Pengalaman Perusahaan \\
\hline
\end{tabular}

Sebagai bahan penilain oleh stakeholder, masing-masing kriteria akan dinilai mengikuti penilaian dengan menggunakan metode skala likter dengan ketentuan :

\section{C1 (Harga)}

Cukup tinggi $(100-200$ juta) $=5$

Tinggi $(200-300$ juta $) \quad=7$

Sangat Tinggi $(>300$ juta $) \quad=9$

C2 (Jumlah Teknisi Professional)

Cukup Banyak (1-4 orang) $\quad=5$

Banyak (4-8 orang) $\quad=7$

Sangat Banyak ( $>=9$ orang) $\quad=9$

C3 (Metodologi Pelaksanaan Pekerjaan)

Cukup Baik $=5$

Baik $=7$

Sangat Baik $=9$

C4 (Pengalaman Perusahaan)

Cukup Baik $=5$

Baik $=7$

Sangat Baik $=9$ 
Tabel. 3 Hasil Penilaian Penilain dari Stakeholder

\begin{tabular}{|c|l|c|c|c|c|}
\hline \multirow{2}{*}{ NO } & \multicolumn{1}{|c|}{ Alternatif } & \multicolumn{4}{|c|}{ Kriteria } \\
\cline { 3 - 6 } & & C1 & C2 & C3 & C4 \\
\hline 1 & PT. Mitra Integrasi Informatika & 7 & 9 & 7 & 9 \\
\hline 2 & PT. Iproteksi Telematika & 5 & 5 & 5 & 5 \\
\hline 3 & PT. Nusa Network Prakarsa & 5 & 9 & 9 & 9 \\
\hline
\end{tabular}

\subsection{Perhitungan pemetaan gap}

Proses perhitungan pemetaan GAP masing-masing vendor akan dinilai langsung oleh stakeholder pada PT Gema Graha Sarana berdasarkan masing-masing kriteria yang sudah ditentukan dengan proses penilaian secara langsung, hasil penilaian tersebut akan dilakukan pencocokan dengan nilai standar yang diinginkan perusahaan, setelah mendaptkan hasil akan diperoleh gap antara nilai profil atribut dengan nilai profil standar, dengan mengikuti rumus persamaan (1)

Tabel 4. Pemetaan GAP

\begin{tabular}{|c|c|c|c|c|c|}
\hline \multirow{2}{*}{ NO } & \multicolumn{2}{|c|}{ Alternatif } & \multicolumn{4}{c|}{ Kriteria } \\
\cline { 3 - 6 } & & C1 & C2 & C3 & C4 \\
\hline 1 & PT. Mitra Integrasi Informatika & 7 & 9 & 7 & 9 \\
\hline 2 & PT. Iproteksi Telematika & 5 & 5 & 5 & 5 \\
\hline 3 & PT. Nusa Network Prakarsa & 5 & 9 & 9 & 9 \\
\hline \multicolumn{2}{r}{ Nilai Standar } & 7 & 9 & 9 & 9 \\
\hline 1 & PT. Mitra Integrasi Informatika & 0 & 0 & -2 & 0 \\
\hline 2 & PT. Iproteksi Telematika & -2 & -4 & -4 & -4 \\
\hline 3 & PT. Nusa Network Prakarsa & -2 & 0 & 0 & 0 \\
\hline
\end{tabular}

\subsection{Melakukan Pembobotan}

Pembobotan dapat dilakukan setelah melakukan perhitungan pemetaan gap, dalam pembobotan ini penulis menggunkan pembobotan nilai gap yang sesudah ditentukan sesuai pada tabel 5 .

Tabel 5. Pembobotan Nilai GAP

\begin{tabular}{|c|c|c|l|}
\hline No & Selisih & Bobot Nilai & \multicolumn{1}{|c|}{ Keterangan } \\
\hline 1 & 0 & 5 & Tidak ada selisih (Kompetensi sesuai yang dibutuhkan) \\
\hline 2 & 1 & 4,5 & Kompetensi individu kelebihan 1 tingkat/level \\
\hline 3 & -1 & 4 & Kompetensi individu kekurangan 1 tingkat/level \\
\hline 4 & 2 & 3,5 & Kompetensi individu kelebihan 2 tingkat/level \\
\hline 5 & -2 & 3 & Kompetensi individu kekurangan 2 tingkat/level \\
\hline 6 & 3 & 2,5 & Kompetensi individu kelebihan 3 tingkat/level \\
\hline 7 & -3 & 2 & Kompetensi individu kekurangan 3 tingkat/level \\
\hline 8 & 4 & 1,5 & Kompetensi individu kelebihan 4 tingkat/level \\
\hline 9 & -4 & 1 & Kompetensi individu kekurangan 4 tingkat/level \\
\hline
\end{tabular}

Setelah nilai gap diperoleh maka langkah berikutnya akan dilakukan konversi ke dalam bobot nilai sesuai dengan ketentuan metode profile matching, sehingga hasil dapat dilihat pada tabel 6 . 
Tabel 6. Konversi Nilai Ke Bobot

\begin{tabular}{|c|l|c|c|c|c|}
\hline \multirow{2}{*}{ NO } & \multirow{2}{*}{ Alternatif } & \multicolumn{4}{|c|}{ Kriteria } \\
\cline { 3 - 6 } & & C1 & C2 & C3 & C4 \\
\hline 1 & PT. Mitra Integrasi Informatika & 0 & 0 & -2 & 0 \\
\hline 2 & PT. Iproteksi Telematika & -2 & -4 & -4 & -4 \\
\hline 3 & PT. Nusa Network Prakarsa & -2 & 0 & 0 & 0 \\
\hline$\quad$ & Konversi Nilai Ke Bobot & & & & \\
\hline 1 & PT. Mitra Integrasi Informatika & 5 & 5 & 3 & 5 \\
\hline 2 & PT. Iproteksi Telematika & 3 & 1 & 1 & 1 \\
\hline 3 & PT. Nusa Network Prakarsa & 3 & 5 & 5 & 5 \\
\hline
\end{tabular}

\subsection{Perhitungan core factor dan secondary factor}

Proses perhitungan core factor dan secondary factor dengan menentukan kriteria-kriteria yang sudah ditetapkan lalu kriteria terbut di pisah menjadi kriteria yang akan dijadikan core factor dan kriteria yang akan dijadikan secondary factor, dalam penilitian ini ada beberapa kriteria yang akan dijadikan core factor, dimana kriteria core factor ini merupakan kriteria paling utama untuk menentukan sebuah keputusan sedangkan untuk secondary factor merupakan kriteria untuk mendukung core factor, adapun yang dijadikan kriteria core factor yaitu : Harga, Jumlah Teknisi Professional, Metodologi Pelaksanaan Pekerjaan $(\mathrm{C} 1, \mathrm{C} 2, \mathrm{C} 4)$, sedaangkan untuk secondary factor Metodologi Pelaksanaan Pekerjaan (C3).

\section{Core Factor}

Untuk menghitung kriteria yang termasuk kedalam core factor menggunakan rumus persamaan (2).

$N C F=\frac{\Sigma N C}{\Sigma I C}$

Keterangan :

NCF : Nilai rata-rata core factor

NC : Jumlah total nilai core factor

IC : Jumlah Item core factor

Proses perhitungancore factor ketiga alternatif vendor yaitu PT. Mitra Integrasi Informatika, PT. Iproteksi Telematika, PT. Nusa Network Prakarsa.
Perhitungan Core Factor untuk ketiga alternatif:

PT. Mitra Integrasi Informatika

$\mathrm{NCF}=\frac{5+5+5}{3}=5$

PT. Iproteksi Telematika

$\mathrm{NCF}=\frac{3+1+1}{3}=1,7$

PT. Nusa Network Prakarsa

$\mathrm{NCF}=\frac{3+5+5}{3}=4,3$

\section{Secondary Factor}

Perhitungan secondary factor dapat dilihat pada rumus persamaan (3)

$\boldsymbol{N S F}=\frac{\Sigma N S}{\Sigma I S}$

Keterangan :

NSF : Nilai rata-rata secondary factor

NS : Jumlah total nilai secondary factor

IS : Jumlah Item secondary factor

Perhitungan secondary factor untuk ketiga alternatif vendor :

PT. Mitra Integrasi Informatika

$\mathrm{NSF}=\frac{3}{1}=3$

PT. Iproteksi Telematika

$\mathrm{NSF}=\frac{1}{1}=1$

PT. Nusa Network Prakarsa

$\mathrm{NSF}=\frac{5}{1}=5$ 
Tabel 7. Hasil Perhitungan Core Factor dan Secondary Factor

\begin{tabular}{|c|l|c|c|c|c|c|c|}
\hline \multirow{2}{*}{ NO } & \multicolumn{1}{|c|}{ Alternatif } & \multicolumn{4}{|c|}{ Kriteria } & Core Factor & $\begin{array}{c}\text { Secondary } \\
\text { Factor }\end{array}$ \\
\cline { 3 - 8 } & & C1 & C2 & C3 & C4 & C1,C2,C4 & C3 \\
\hline 1 & $\begin{array}{l}\text { PT. Mitra Integrasi } \\
\text { Informatika }\end{array}$ & 5 & 5 & 3 & 5 & 5 & 3 \\
\hline 2 & PT. Iproteksi Telematika & 3 & 1 & 1 & 1 & 1,7 & 1 \\
\hline 3 & PT. Nusa Network Prakarsa & 3 & 5 & 5 & 5 & 4,3 & 5 \\
\hline
\end{tabular}

\subsection{Perhitungan nilai total}

perhitungan nilai total diperolah dari pembagian dari presentase dari nilai core factor dan secondary factor. presentase core factor sebesar $60 \%$ dan secondary factor sebesar $40 \%$, untuk proses perhitungan nilai total menggunakan rumus persamaan (4).

$\mathrm{N}($ Kriteria $)=(\mathrm{x}) \% * \mathrm{NCF}(\mathrm{C} 1, \mathrm{C} 2, \mathrm{C} 4)+$ (x) $\% * \operatorname{NSF}(\mathrm{C} 3)$

Keterangan:

NCF $(C 1, C 2, C 4)$ :Nilai rata-rata core factor $(\mathrm{C} 1, \mathrm{C} 2, \mathrm{C} 4)$

NSF (C3)

factor (C3)

$\mathrm{N}$ (Kriteria)
:Nilai rata-rata secondary

:Nilai total dari aspek (x)\% : Nilai persen yang diinputkan.

\section{Perhitungan nilai total:}

PT. Mitra Integrasi Informatika

$N=(60 \% * 5.0)+(40 \% * 3)$

$=3+1.2$

$=4.2$

PT. Iproteksi Telematika

$N=(60 \% * 1.7)+(40 \% * 1)$

$=1+0.4$

$=1.4$

PT. Nusa Network Prakarsa

$N=(60 \% * 4.3)+(40 \% * 5)$

$=2.6+2$

$=4.6$

Tabel 8. Hasil Perhitungan Nilai Total

\begin{tabular}{|c|l|c|c|c|}
\hline NO & Alternatif & Core Factor & $\begin{array}{c}\text { Secondary } \\
\text { Factor }\end{array}$ & Nilai Total \\
\hline 1 & PT. Mitra Integrasi Informatika & 5 & 3 & 4,2 \\
\hline 2 & PT. Iproteksi Telematika & 1,7 & 1 & 1,4 \\
\hline 3 & PT. Nusa Network Prakarsa & 4,3 & 5 & 4,6 \\
\hline
\end{tabular}

\subsection{Proses perangkingan}

Proses perengkingan ini merupakan kelanjutan langkah dari proses perhitungan nilai total, kerena dalam penelitian ini hanya menggunakan empat kriteria dalam proses pengolahan datanya, dan tidak menggunakan kriteria-kriteria lain maka tidak lakukan perhitungan prentase perengkingan dengan melihat dari hasil nilai total sudah dapat ditentukan rengking vendor yang akan dipilih untuk di ajak kerjasama dalam melakukan maintenance server dan jaringan dengan urutan rangking satu PT. Nusa Network Prakarsa, rangking dua PT. Mitra Integrasi Informatika, dan rengking tiga PT. Iproteksi Telematika. Dengan melihat dari hasil perengkingan perusahaan mengambil keputusan dengan memilih vendor dari PT. Nusa Network Prakarsa.

\section{Kesimpulan}

Setiap Perusahaan perlu untuk memilih vendor yang tepat serta dapat bekerja sama dengan baik. Pemilihan vendor yang tepat dilakukan dengan melihat kriteria vendor tersebut sehingga diharapkan dapat meminimalkan resiko yang akan timbul. Penggunanaan Metode Profile Matching dapat memudahkan pihak manajemen dalam mengambil sebuah keputusan yang tepat, sehingga hal-hal yang tidak diinginkan dapat dihindari, karena proses pengambil keputusannya sudah menggunakan sistem, pihak manajemen mangambil salah satu alternatif vendor yang akan diajak kerja sama dalam memaintenance server dan jaringian di PT. GemaGrahaSarana dengan memilih vendor, PT. Nusa Network Prakarsa dengan perolehan nilai 4,6. 
Saran pada penelitian berikutnya dapat membandingkan antar metode yaitu metode profile matching dengan metode sistem pendukung keputusan yang lainya, sehingga diketahui kelebihan dan kekurang dari masing-masing metode tersebut, selain itu sistem yang dihasilkan dari penelitian ini dapat juga digunakan untuk kasus lain atau untuk instansi lain, tetapi hal ini memerlukan evaluasi lebih lanjut pada kriteria penilaian yang akan digunakan.

\section{Referensi}

Adhar, D. (2014). Sistem Pendukung Keputusan Pengangkatan Jabatan Karyawan pada PT. Ayn dengan Metode Profile Matching. Jatisi, $x(\mathrm{x})$, 16-29.

Arini, D. (2015). Analisis Pemilihan Vendor Dengan Menggunakan Pendekatan Metode Fuzzy Topsis Di PT. Tripatra Engineers And Constructors. Jurnal IImiah Teknik Industri, 3(1), 53-58.

Hakim, Z., Sudiarjo, A., \& Efrida, R. (2017). Rancangan Sistem Penunjang Keputusan Pengangkatan Karyawan Tetap Dengan Metode Profile Matching di PT . Lotte Packaging. SISFOTEK GLOBAL, 7(2), 13-19.

Kurniawan, R., Hasibuan, S., \& Nugroho, R. E. (2017). Analisis Kriteria Dan Proses Seleksi Kontraktor Chemical Sektor Hulu Migas: Aplikasi Metode DelphiAHP. Jurnal IImiah Manajemen, VII(2), 252-266.

Kusrini. (2007). Konsep dan Aplikasi Sistem Pendukung Keputusan. Yogyakarta: Andi Offset.

Mufid, A. (2014). Sistem Pendukung Keputusan Penilaian Proposal Kegiatan PNPM MPd Menggunakan Metode Profile Matching dan Analytic Hierarchy Process ( AHP ). Jurnal Sistem Informasi Bisnis, 1, 40-47.

Permana, A. A. J. (2016). Sistem Pendukung Keputusan Penentuan Supplier Suku Cadang Mobil Pabrikan Eropa Dalam Konteks Interaksi Manusia Komputer. JANAPATI, 5(3), 142-148.
Pohan, F., \& Wibowo, A. (2017). Integrasi Model Pendukung Keputusan Evaluasi Pemilihan Vendor Dengan Fuzzy Analytical Network Process dan TOPSIS Studi Kasus PT Samudera Indonesia Ship Management. Tehnik, 6(2), 83-91.

Sutinah, E. (2017). Sistem Pendukung Keputusan Menggunakan Metode Profile Matching Dalam Pemilihan Salesman Terbaik. Informatics For Educators And Professionals, 2(1), 29-42. 